\title{
Bacteremic pneumonia caused by penicillin-resistant pneumococci: Case report and review with a Canadian perspective
}

DAVID R BURDGE, MD, FRCPC, VINCENT C WOO, MD, PATRICIA MA RITCHE, MB, CHB, FRCPC

\begin{abstract}
DR BURDGe, VC Woo, PMA RITCHIE. Bacteremic pneumonia caused by penicillin-resistant pneumococci: Case report and review with a Canadian perspective. Can $J$ Infect Dis 1992:3(4):185-188. A Canadian adult with bacteremic pneumonia caused by a relatively penicillin-resistant (minimal inhibitory concentration $0.25 \mu \mathrm{g} / \mathrm{mL}$ ) Streptococcus pneumoniae is reported, and the published literature regarding penicillin-resistant pneumococci in Canada reviewed. Althomgh penicillin resistance has been reported infrequently to date, this case emphasizes the need for routine antimicrobial sensitivity testing of all pneumococci isolated from normally sterile sites, and for ongoing systematic surveillance for penicillin and other antibiotic resistance in Canada.
\end{abstract}

Key Words: Penicillin-resistant pneumococci, Penicillin-resistant Streptococcus pneumoniae, Pneumococci, Streptococcus pneumoniae

\section{Pneumonie bactériémique due à des pneumocoques résistants à la pénicilline: Observation et aperçu de la littérature canadienne}

RÉSUMÉ: L'auteur rapporte le cas d'un Canadien adulte porteur d'une pneumonie bactériémique causée par un Streptococcus pneumoniae relativement résistant à la pénicilline (concentration inhibitrice minimale $0,25 \mathrm{ug} / \mathrm{mL}$ ). Il passe en revue la littérature publiée au Canada à ce sujet. Bien que la résistance à la pénicilline ait peu été rapportée jusqu'à présent, ce cas rappelle qu'il est important de procéder aux antibiogrammes de routine pour tous les pneumocoques isolés à partir de sites normalement stériles, et de surveiller systématiquement la résistance à la pénicilline et aux autres antibiotiques au Canada.

Division of Infectious Diseases, Division of Microbiology. Department of Laboratory Medicine. University Hospital - Shaughnessy Site, University of British Columbia, Vancouver, British Columbia

Correspondence and reprints: Dr David R Burdge, Division of Infectious Diseases, Room G61 1 - Jean Matheson Pavilion. University Hospital - Shaughnessy Site, 4500 Oak Street, Vancouver, British Columbia V6H 3N1. Telephone (604) 875-2213, Fax (604) 875-2703

Received for publication May 28, 1991. Accepted August 26, 1991 
P ENICILLIN G REMAINS THE ANTIMICROBIAL AGENT OF choice for the treatment of pneumococcal infections. Since 1967, however, when a pneumococcus that was relatively resistant to penicillin was first reported from Australia (1), an increasing prevalence of both relatively resistant (minimal inhibitory concentration [MIC] 0.12 to $1.0 \mu \mathrm{g} / \mathrm{mL}$ ) and resistant (MIC greater than or equal to $1.0 \mu \mathrm{g} / \mathrm{mL}$ ) pneumococci has been noted in many parts of the world (2).

To date, penicillin-resistant pneumococci have been infrequently reported from Canada. The authors present the case of an adult from Vancouver, British Columbia who developed bacteremic pneumococcal pneumonia with an isolate that was relatively resistant (MIC $0.25 \mu \mathrm{g} / \mathrm{mL}$ ), and review the published literature regarding penicillin-resistant pneumococci in Canada.

\section{CASE PRESENTATION}

A 68-year-old man was admitted to hospital with a diagnosis of right lower lobe pneumonia. Past medical history was significant for myocardial infarction at age 33 years and for repair of perforated peptic ulcer one year prior to admission. He was a heavy smoker and consumed six to eight ounces of alcohol daily. The patient was on no medication, had not been recently hospitalized, and had not received any recent antimicrobial therapy.

Physical examination revealed a blood pressure of $110 / 70 \mathrm{mmHg}$, a heart rate of 130 beats/min and a temperature of $38.3^{\circ} \mathrm{C}$. The respiratory rate was $23 /$ min, and there were findings consistent with right lower lobe consolidation. The remainder of the physical examination was normal. Investigations revealed a hemoglobin of $122 \mathrm{~g} / \mathrm{L}$ and a white blood cell count of $21.9 \times 10^{9} / \mathrm{L}$. Arterial blood gas analysis on room air revealed $\mathrm{pH} 7.51, p \mathrm{O}_{2} 51 \mathrm{mmHg}$ and $\mathrm{pCO}_{2} 28 \mathrm{mmHg}$. Gram stain of expectorated sputum revealed more than 25 epithelial cells per low power field, and the specimen was deemed unacceptable for culture. Chest $\mathrm{x}$-ray showed an infiltrate consistent with right lower lobe pneumonia.

The patient was treated with oxygen, intravenous thiamine and intravenous cefuroxime $1.5 \mathrm{~g}$ every $8 \mathrm{~h}$. Blood cultures taken on admission grew Gram-positive cocci in chains $24 \mathrm{~h}$ later. Cefuroxime was discontinued and intravenous penicillin G two million units every $6 \mathrm{~h}$ was commenced. Two days after admission, there was sudden clinical deterioration with respiratory distress, decreased level of consciousness and cyanosis. The patient was transferred to the intensive care unit and required intubation and mechanical ventilation. Electrocardiography and cardiac enzymes were consistent with acute myocardial infarction. Chest $\mathrm{x}$-ray showed new bilateral basilar infiltrates, and antibiotic therapy was changed to intravenous imipenem $1 \mathrm{~g}$ every $8 \mathrm{~h}$ to treat probable hospital-acquired aspiration pneumonia superimposed on the pneumococcal pneumonia.
Two sets of blood cultures drawn on admission to hospital grew Streptococcus pneumoniae. The organism was reported to be resistant to penicillin and sensitive to ampicillin, erythromycin, clindamycin, vancomycin, chloramphenicol, tetracycline and imipenem. Imipenem therapy was continued and the patient slowly recovered. Follow-up blood cultures on imipenem therapy were sterile. Unfortunately, 20 days after admission, the patient suffered acute cardiopulmonary arrest and died, despite attempts at resuscitation. Autopsy revealed the cause of death to be a new myocardial infarction. Histopathological examination of the lungs revealed an organizing pneumonia with diffuse alveolar damage, but no acute inflammatory infiltrate. No Gram-positive diplococci were demonstrated on tissue Gram smears.

\section{MICROBIOLOGICAL METHODS AND RESULTS}

Blood culture isolates of Strep pneumoniae were identified according to standard methods. Susceptibility testing was performed at the University Hospital (Shaughnessy site) microbiology laboratory by modified Kirby-Bauer procedure using a $1 \mu \mathrm{g}$ oxacillin disk on Mueller-Hinton agar supplemented with 5\% lysed horse blood. MIC testing to penicillin was performed by microbroth dilution technique (Sensititre; Radiometer/ Copenhagen Co, Ohio) using a supplementation of 5\% sheep blood, as described by D'Amato et al (3). Enterococcus faecalis ATCC strain 29212 was used as a control. Two different morphotypes were observed on subculture to sheep blood agar which gave zone sizes of 0 and $11.5 \mathrm{~mm}$, respectively, to a $1 \mu \mathrm{g}$ oxacillin disk. Both were susceptible to tetracycline, ampicillin, erythromycin, clindamycin, vancomycin and imipenem. The MIC of penicillin for both morphotypes was $0.25 \mu \mathrm{g} / \mathrm{mL}$. The organism was serotyped as type 14 by the National Centre for Streptococci at the Provincial Laboratory of Public Health in Edmonton, Alberta.

\section{DISCUSSION}

The first report of a penicillin-resistant pneumococcus came from Australia in 1967 (1). Since then, resistant strains have been reported from many countries. and in some areas the prevalence of penicillin-resistant pneumococci is now extremely high. In South Africa, for example, 8.4 to $62.2 \%$ of pneumococcal isolates have an MIC greater than or equal to $0.1 \mu \mathrm{g} / \mathrm{mL}$ (2). Other areas with high rates of resistance (MIC greater than or equal to $0.1 \mu \mathrm{g} / \mathrm{mL}$ ) include Spain $(19.5$ to $52 \%)(4,5)$, Israel (28.4\%) (6), Poland (26.7\%) (2) and New Guinea (12.5 to $33.3 \%$ ) (7). Serial surveillance reveals that rates and degree of penicillin resistance are increasing in many of these areas. For example, Klugman and Koornhof (8) surveyed blood culture isolates in South Africa and found that, in 1979, 3.8\% of isolates were penicillin resistant (MIC greater than or equal to 0.1 $\mu \mathrm{g} / \mathrm{mL}$ ), while in $1986,14.1 \%$ of isolates were resistant. 
Isolates with resistance to multiple antibiotics are also being reported with increasing frequency.

In the United States, there is considerable variability in the prevalence of penicillin-resistant pneumococci from region to region. The Centers for Disease Control conducted a national surveillance study from 1979 through 1985 and found that 126 of 3400 isolates $(3.7 \%)$ from normally sterile body sites (cerebrospinal fluid, blood) were relatively penicillin resistant (MIC 0.1 to $1.0 \mu \mathrm{g} / \mathrm{mL}$ ) (9). There was only one isolate that was resistant (MIC $4 \mu \mathrm{g} / \mathrm{mL}$ ). However, surveys of specific populations or geographic areas have demonstrated much higher rates of resistance, including 22 of 197 (11.2\%) in Alaska (10) and 17 of $139(12.2 \%)$ in Oklahoma City (11).

The first major Canadian survey of Strep pneumoniae was reported by Dixon et al (12) in which 6000 clinical isolates obtained from northern Alberta and the adjacent Northwest Territories during 1974-76 were studied. Relative resistance to penicillin (MIC greater than or equal to $0.16 \mu \mathrm{g} / \mathrm{mL}$ ) was detected in 143 isolates (2.4\%) which came from the nasopharynx (96), ear (32), eye (eight), sputum (five) and skin (two). None of the organisms was isolated from blood or a normally sterile site, and the majority of isolates were from children under six years of age. None of the isolates demonstrated high level resistance. Another large survey of outpatient isolates was performed in Ontario in 1988, revealing relative penicillin resistance (MIC 0.12 $\mu \mathrm{g} / \mathrm{mL}$ to $1.0 \mu \mathrm{g} / \mathrm{mL})$ in eight of 551 specimens $(1.5 \%)$ (13). The eight relatively resistant isolates were all cultured from swabs of nose, eyes, ears and throat from children.

Invasive infection with penicillin-resistant pneumococci has been reported from Canada. A survey of isolates from blood or other sterile body fluids done in Quebec from 1984-86 revealed relative penicillin resistance (MIC 0.12 to $1.0 \mu \mathrm{g} / \mathrm{mL}$ ) in six of 468 isolates (1.3\%) (14). Furthermore, individual cases of serious

\section{REFERENCES}

1. Hansman D, Bullen MM. A resistant pneumococcus. Lancet 1967:ii:264-5.

2. Appelbaum PC. Worldwide development of antibiotic resistance in pneumococci. Eur $\mathrm{J}$ Clin Microbiol 1987;6:367-77.

3. D'Amato RF, Swenson JM, McKinley GA, et al. Quantitative antimicrobial susceptibility testing for Streptococcus pneumoniae using inoculum supplemented with whole defibrinated sheep blood. J Clin Microbiol 1987;25;1753-7.

4. Casal J, Fenoll A, Vicioso MD, et al. Increase in resistance to penicillin in pneumococci in Spain. Lancet 1989;i:735.

5. Latorre C. Juncosa T, Sanfeliu I. Antibiotic resistance and serotypes of 100 Streptococcus pneumoniae strains isolated in a children's hospital in Barcelona, Spain. Antimicrob Agents Chemother 1985;28:357-9.

6. Michel J, Dickman D, Greenberg Z, et al. Serotype distribution of penicillin-resistant pneumococci and their pneumococcal disease due to relatively penicillin-resistant organisms have been reported $(15,16)$. To date, only three instances of high level penicillin resistance have been described. Lapointe and Joncas $(16,17)$ reported an infant with meningitis due to a resistant Strep pneumoniae (MIC $2.0 \mu \mathrm{g} / \mathrm{mL}$ ) successfully treated with high dose ampicillin. The same authors also described the case of a three-week-old Inuit female with pneumonia, in which a resistant pneumococcus (MIC $2.0 \mu \mathrm{g} / \mathrm{mL}$ ) was isolated from tracheal secretions (16). This infant responded well to erythromycin therapy. Finally, Kibsey (18) reported the case of a five-year-old child who developed fatal bacteremic pneumonia with a multiply resistant Strep pneumoniae (MIC $2 \mu \mathrm{g} / \mathrm{mL}$ ).

Pneumococci with increased resistance to beta-lactam antibiotics do not produce beta-lactamase enzymes. Rather, resistance is associated with alterations in penicillin-binding proteins (19). Optimal treatment of infections due to these organisms depends on the degree of resistance, the site of infection, and the pattern of resistance to alternative antibiotics $(20,21)$. High dose penicillin may be adequate for infection with relatively resistant strains outside of the central nervous system (22). However, meningitis will often fail to respond to even high dose penicillin therapy. Therefore central nervous system infections should be treated with cidal drugs that penetrate the blood-brain barrier. chosen on the basis of in vitro sensitivity data. Imipenem, cefotaxime or vancomycin are likely to be effective $(2,23)$.

In summary, to date, penicillin-resistant pneumococci are unusual in Canada. The present authors have reported a case of bacteremic pneumonia in a Canadian adult caused by Strep pneumoniae with relative resistance to penicillin. The case emphasizes the importance of routine sensitivity testing for clinical isolates from sterile sites, and also emphasizes the need for continuing surveillance of pneumococci for penicillin and other antibiotic resistance in Canada.

susceptibilities to seven antimicrobial agents. Antimicrob Agents Chemother 1983;23:397-401.

7. Gratten M, Naraqi S, Hansman D. High prevalence of penicillin-insensitive pneumococci in Port Moresby, Papua, New Guinea. Lancet 1980;ii:192-5.

8. Klugman KP, Koornhof HJ. Drug resistance patterns and serogroups or serotypes of pneumococcal isolates from cerebrospinal fluid or blood, 1979-1986. J Infect Dis 1988; 158:956-64.

9. Spika JS, Facklam RR, Plikaytis BD, Oxtoby MJ, and the Pneumococcal Surveillance Working Group. Antimicrobial resistance of Streptococcus pneumoniae in the United States, 1979-1987. J Infect Dis 1991:163:1273-8.

10. Parkinson AJ, Heyward WL, Facklam RR, et al. Partial penicillin resistance of Streptococcus pneumonice isolates recovered from Alaskan Eskimos. Program and abstracts of the 26th Intersciences Conference on Antimicrobial Agents and Chemotherapy. New Orleans: American Society for Microbiology, 1986. (Abst 710)

11. Istre GR, Tarpay M, Anderson M, et al. Invasive disease 
due to Streptococcus pneumoniae in an area of high rate of relative penicillin resistance. J Infect Dis 1987:156:732-5.

12. Dixon JMS, Lipinski AA, Graham MEP. Detection and prevalence of pneumococci with increased resistance to penicillin. Can Med Assoc J 1977;117:1159-61.

13. Mazzulli T, Simor AE, Jaeger R, Fuller S, Low DE. Comparative in vitro activities of several new fluoroquinolones and beta-lactam antimicrobial agents against community isolates of Streptococcus pneumoniae. Antimicrob Agents Chemother 1990;3:467-9.

14. Jette LP, Lamothe F, and the Pneumococcus Study Group. Surveillance of invasive Streptococcus preumoniae infection in Quebec, Canada from 1984-1986: Serotype, distribution, antimicrobial susceptibility and clinical characteristics. J Clin Microbiol 1989;27:1-5.

15. Ahronheim GA, Reich B, Marks MI. Penicillin-insensitive pneumococci; case report and review. Am J Dis Child 1979; 133:187-91.

16. Lapointe JR, Joncas JH. Penicillin-resistant and multiresistant pneumococcal strains - Quebec. Can Dis Weekly Rep 1982;8:133-5.

17. Lapointe JR, Joncas JH. Meningitis in a Canadian infant due to pneumococcus resistant to penicillin and chloramphenicol. J Pediatr 1983;103:580-2.

18. Kibsey PC. A case of multiply-resistant Streptococcus pneumoniae - Alberta. Can Dis Weekly Rep 1986;12:13-4.

19. Handwerger S, Tomasz A. Alterations in penicillinbinding proteins of clinical and laboratory isolates of pathogenic Streptococcus pneumoniae with low levels of penicillin resistance. $J$ Infect Dis 1986;153:83-9.

20. Ward J. Antibiotic-resistant Streptococcus pneumoniae: Clinical and epidemiological aspects. Rev Infect Dis 1981:3:254-66.

21. Mufson MA. Streptococcus pneumoniae. In: Mandell GL, Douglas RG Jr, Bennett JC, eds. Principles and Practice of Infectious Diseases, 3rd edn. New York: Churchill Livingstone, 1990: 1539-50.

22. Pallares R, Gudiol F, Linares J, et al. Risk factors and response of antibiotic therapy in adults with bacteremic pneumonia caused by penicillin-resistant pneumococci. N Engl J Med 1987;317:18-22.

23. Viladrich PF, Gudiol F, Linares J. Characteristics and antibiotic therapy of adult meningitis due to penicillin-resistant pneumococci. Am J Med 1988;84:839-46. 


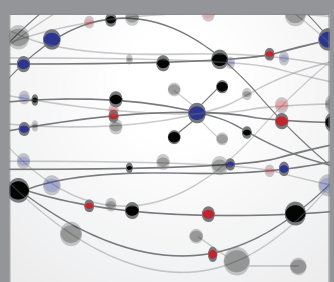

The Scientific World Journal
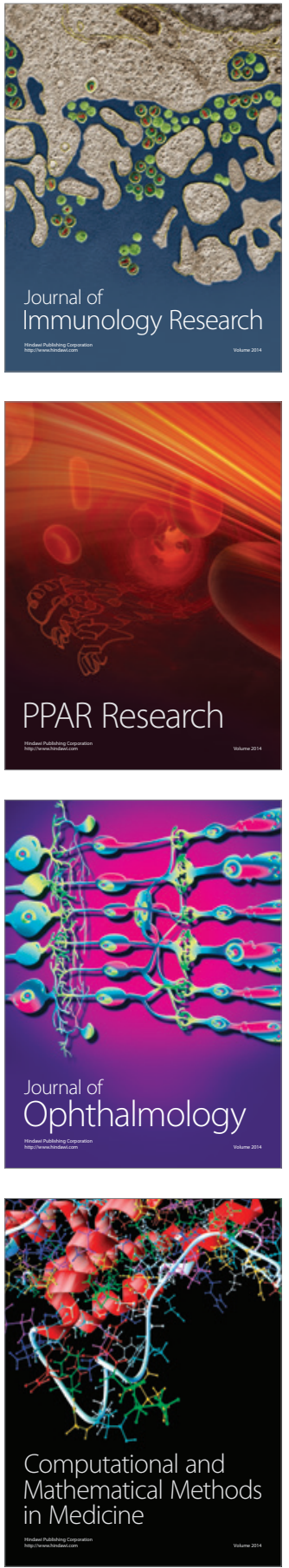

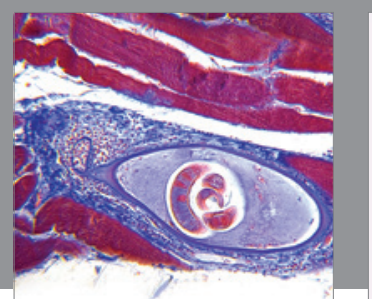

Gastroenterology Research and Practice

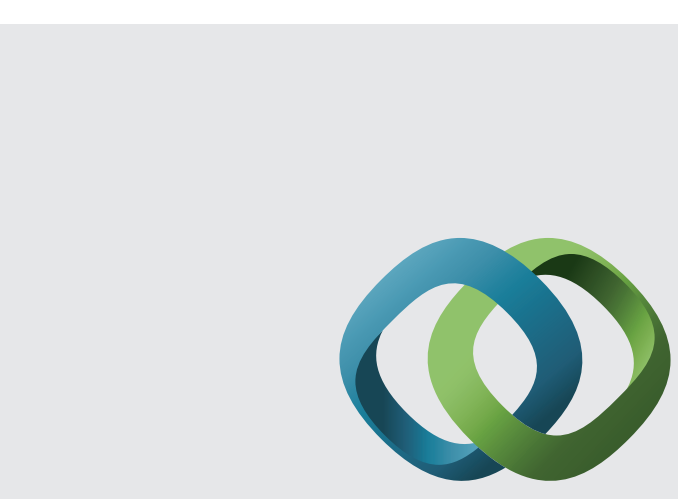

\section{Hindawi}

Submit your manuscripts at

http://www.hindawi.com
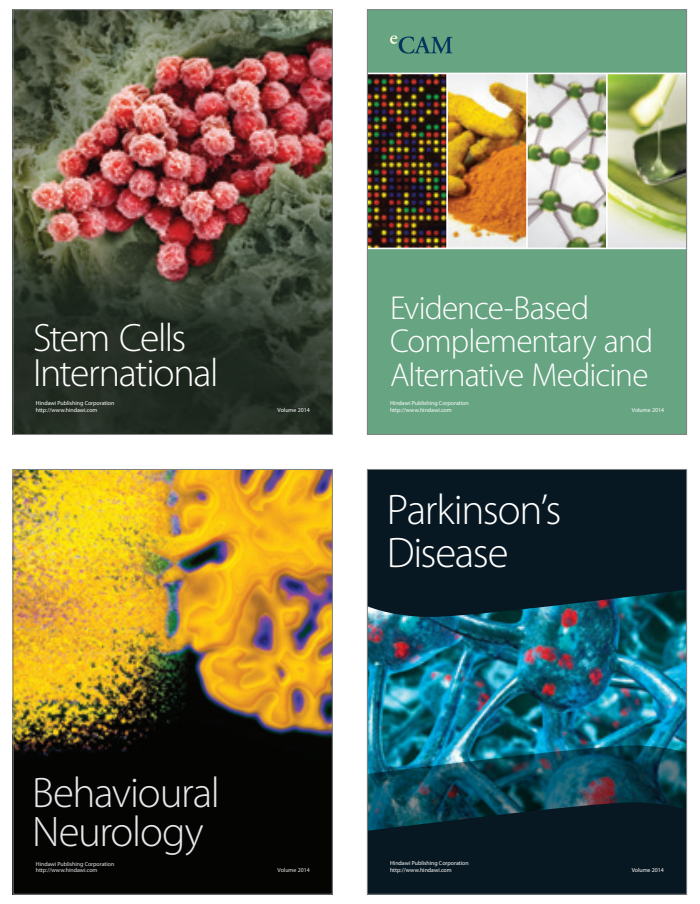
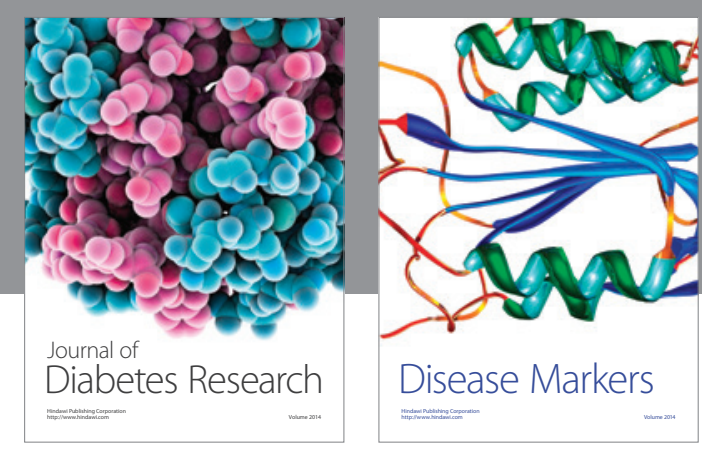

Disease Markers
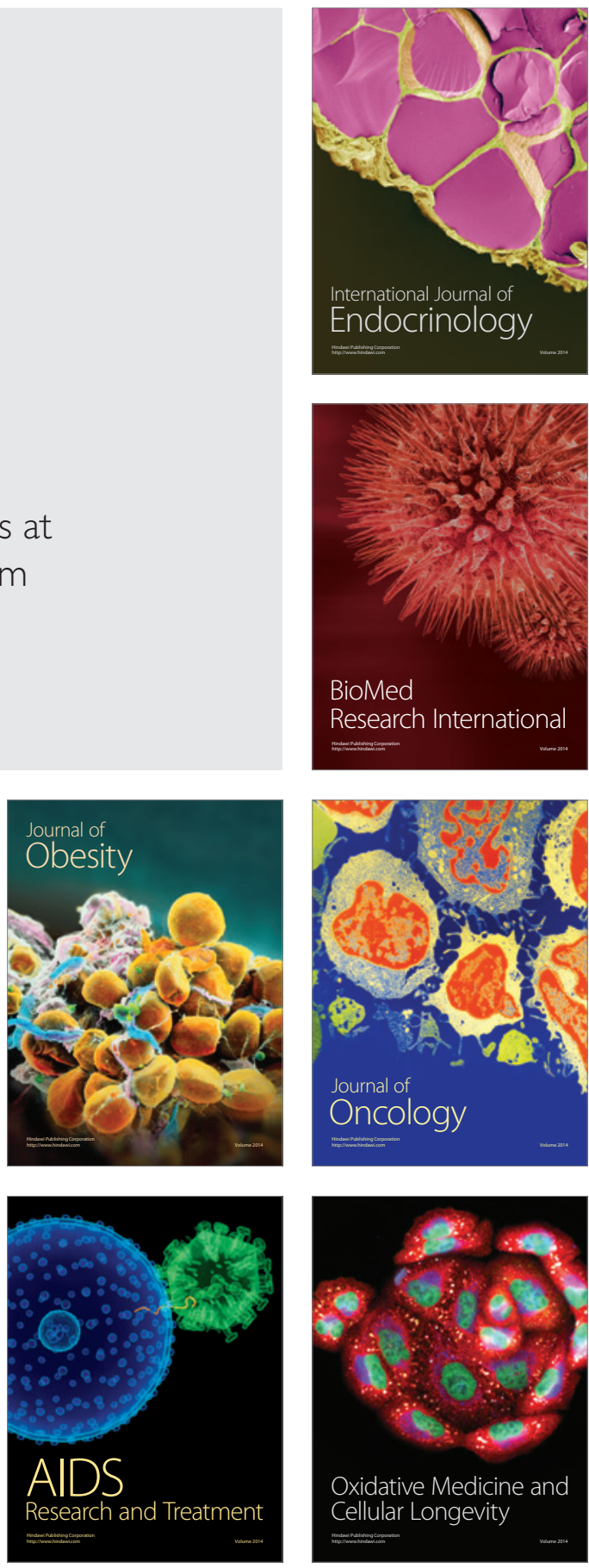